\title{
A caracterização dos livros digitais a partir de sua materialidade
}

\author{
Thaís Cristina Martino Sehn* \\ Suely Fragoso** \\ José Luís Farinatti Aymone ${ }^{\dagger}$
}

\section{Introdução}

Se outrora a leitura digital era associada à imobilidade dos computadores de mesa, hoje é notório que muitas pessoas estão explorando as possibilidades dos aparelhos móveis para dar andamento às suas leituras. Os tablets, ${ }^{1} e$-readers ${ }^{2} \mathrm{e}$ smartphones $^{3}$ são novos suportes digitais que entram na vida dos leitores brasileiros cada vez com mais força. Além de seu grande potencial para ampliar o acesso aos livros digitais ${ }^{4}$ e de sua mobilidade, esses aparelhos acrescentam novas possibilidades de recursos e linguagens para serem utilizados nesse tipo de publicação.

As novas configurações que passam a ser possíveis com a digitalização dos livros colocam em xeque a própria definição sobre o que é ou possa vir a ser um livro, até porque, ao migrar para o digital, as divergências não se encerram somente na transposição da representação do papel para os pixels. É certo afirmar que pode a estrutura do livro permanecer inalterada, mas também é possível ex-

* Doutoranda em Design pela Universidade Federal do Rio Grande do Sul (UFRGS), Porto Alegre, RS, Brasil. E-mail: crisehn@gmail.com.

** Professor titular do PGDesign UFRGS, Porto Alegre, RS, Brasil. E-mail: suelyfragoso@ufrgs.br.

† Doutor em Engenharia pela Universidade Federal do Rio Grande do Sul (UFRGS). E-mail: aymone@ufrgs.br.

1 Tablet é um tipo de computador portátil, de tamanho pequeno, fina espessura e com tela sensível ao toque (touchscreen).

2 E-reader é um aparelho portátil criado especificamente para a leitura de livros digitais. Normalmente sua tela possui tecnologia $e-I n k$, a qual não emite luz. A tela pode ser sensível ao toque ou não.

3 Smartphone é um telefone celular com tecnologias avançadas, o que inclui programas executáveis em um sistema operacional, equivalente ao dos computadores. A tradução literal do termo seria telefone inteligente.

4 Neste trabalho optou-se por dar preferência ao termo livro digital, mas para tornar a leitura mais agradável e o termo menos repetitivo, fez-se também uso como sinônimos de $e$-book e livro eletrônico. 
plorar os recursos do meio digital, fazendo uso de suas potencialidades, tal como interatividade, hipertexto, linguagens multimídia e interação entre leitores.

No Brasil uma das formas mais conhecidas de livro digital é o arquivo PDF (Portable Document Format), cuja principal característica é justamente a fidedignidade, pois esse tipo de arquivo se apresenta na tela tal qual a configuração visual prevista para o impresso. Contudo, seria redutor pensar em livros digitais apenas como arquivos que reproduzem as características do papel, mesmo porque a visualização do texto na tela já implica configurações específicas, diferentes das do impresso, posto que solicitam um novo design capaz de dar conta, por exemplo, dos diferentes formatos e dimensões de telas que exigem alterações das margens, das cores, do tamanho e do tipo da fonte. Diante da fluidez desses novos aparelhos, a diagramação pensada para a rigidez do papel pode causar desconforto, sobretudo em aparelhos pequenos, como e-readers e smartphones. Para solucionar essa dificuldade, foi desenvolvido o formato de arquivo EPuB (Eletronic Publication), no qual as informações textuais são independentes das configurações visuais, possibilitando que a cada visualização em uma tela o texto se reacomode no visor, facilitando a leitura contínua.

O meio digital também possibilita a utilização de recursos multimidiáticos, tais quais vídeos, sons, imagens e animações; inclusive trazendo consigo outras formas de interatividade a serem ativadas pelo leitor, que podem ser realizadas com os elementos do livro (através de hipertextos, animações, vídeos etc.), recursos esses que são programados para responder à ação do usuário.

Ao se explorar as potencialidades do meio digital, podem ser repetidas as convenções já estabelecidas na cultura impressa, produzir-se uma reconfiguração do livro que não o descaracterize, mesmo que utilizando novos recursos permitidos pelo suporte digital ou, ainda, criar-se um modelo inusitado de transmissão de conhecimento, configurando um artefato que já não seria mais considerado um livro. Neste momento de implantação de novas tecnologias e exploração de suas potencialidades, é relevante saber quais desses caminhos estão sendo tomados pelas produções editoriais. Frente a essas possibilidades, através desta pesquisa visa-se responder à pergunta: como se configura o cenário das publicações digitais no momento atual?

\section{Metodologia}

A pesquisa foi feita com base em revisão bibliográfica e observação do objeto de estudo: os livros digitais. A pesquisa teórica permeou todas as etapas da pesquisa e foi fundamental para a identificação das características historicamente associadas à noção de livro. Para a observação dos livros digitais partiu-se de uma amostra intencional, uma vez que se tratava de buscar as características de um artefato emergente, ainda em fase de desenvolvimento e experimentação (Fragoso; Recuero; 
AmARAL, 2012). A amostra assim constituída foi submetida a uma análise formal, com categorias descendentes e ascendentes, que será brevemente descrita a seguir.

Para a construção da amostra, foram selecionados livros digitais informacionalmente ricos (PATTON, 2003), de forma a ressaltar as características e potencialidades do cenário em estudo. Além disso, optou-se por publicações que fossem preferencialmente - mas não apenas - em português, uma vez que a pesquisa estava sendo feita no Brasil e o acesso era facilitado nos aparelhos comercializados no país. ${ }^{5} \mathrm{O}$ processo de amostragem foi concluído por meio de saturação (Fragoso, ReCuero; AmAral, 2012), resultando em uma amostra final de 82 livros digitais.

Para realizar a análise dos livros coletados foi desenvolvido um instrumento de análise próprio com categorias ascendentes e descendentes, inspirado na Teoria Fundamentada (Fragoso; Recuero; Amaral, 2012) e na Análise de Conteúdo (BARDIN, 2011). O processo foi constituído de seis etapas. As duas primeiras, corresponderam à codificação aberta e à codificação axial (Fragoso; ReCuero; AMARAL, 2012). A terceira consistiu de uma análise piloto, direcionada a um dos livros da amostra, que tinha a peculiaridade de ter sido lançado simultaneamente em quatro formatos (impresso, PDF, MOBI, EPUB), com diferenças de projeto gráfico conforme as especificidades de cada suporte. As verificações dessa análise piloto foram combinadas com o referencial teórico, resultando em uma primeira tabela de análise (quarta etapa), que foi testada com três livros digitais, pertencentes a categorias diferentes entre as estabelecidas até então. Na quinta etapa, realizou-se um balanceamento retomando as características das codificações aberta e axial, o que resultou em uma nova versão da tabela de análise. A partir de mais três estudos-piloto, foram feitas modificações que geraram a tabela final do estudo (sexta etapa). ${ }^{6}$

Através do confronto das características e potencialidades apontadas na teoria com aquelas observadas nos exemplos estudados, enumerou-se os diferentes tipos de produções que estão sendo chamadas de livros digitais e se verificou como estes se diferenciavam a partir de sua materialidade e dos recursos explorados nos mesmos. A partir da revisão bibliográfica foi construído um conjunto de parâmetros para refletir o livro, visando contemplar tanto o impresso quanto o digital, desvinculando a necessidade de ser produzido em um suporte impresso. Neste artigo, faz-se um resgate dos principais pontos abordados no embasamento teórico

5 As pesquisas realizadas no Google buscam os resultados nos sites que estão mais próximos geograficamente do buscador, através do IP do computador utilizado. Além disso, há outros impedimentos: a loja virtual da Apple, por exemplo, exige um cadastro com endereço, que impede que o usuário de um país compre na loja virtual de outro.

6 Os pormenores da construção desse instrumento de análise, assim como das categorias de análise, encontram-se publicados em maior detalhe no artigo "Um Retrato dos Livros Digitais: desenvolvimento de instrumental metodológico para estudo empírico", de Sehn e Fragoso (2014). Disponível em: http://www.proceedings.blucher.com.br/article-details/12895. DOI: 10.5151/designproped-oo679. 
da dissertação ${ }^{7}$ de mestrado de Comunicação e Informação de um dos autores, assim como dos resultados obtidos com o estudo.

\section{O livro impresso a partir de sua materialidade}

O livro é um objeto cuja história se mistura com a leitura, sendo esta uma prática que pode ser comparada a um jogo, pelo qual o leitor, através dos índices verbais e não-verbais apresentados, elabora hipóteses a serem confirmadas, descartadas e/ou reconfiguradas ao longo do texto. Nesse ato, o resultado depende de "dois conjuntos de fatores: (1) os relacionados aos leitores e às comunidades de interpretação nas quais estão inseridos; e (2) os relacionados aos textos e a sua materialidade" (ChArtier, 1996 $6^{8}$ apud Gruszynski, 2007, p. 121). Este estudo se debruça sobre o segundo grupo de fatores, mais especificamente naquele que tange ao aspecto da materialidade, refletindo sobre como a transposição do texto para os suportes digitais altera as potencialidades de mediação editorial do livro digital e interfere diretamente no produto final que chega ao leitor.

O projeto gráfico de um livro, ao ser elaborado, objetiva construir um sentido, direcionar o leitor para um conjunto de expectativas, que poderão ser confirmadas ou reformuladas ao longo da leitura (GRUSZYNSKI, 2007). Entretanto, muitos leitores não têm consciência dessa ação, pois no momento da leitura a sua atenção é voltada ao significado das palavras e não à forma como em que ele é enunciado. (GrusZynsKi, 2007). Essa passagem do visual para o sonoro resulta num efeito de "invisibilidade" da formatação da palavra escrita. Todavia esse fenômeno não significa que o leitor está "imune" aos estímulos dados pela materialidade do texto (Gruszynski, 2007; Chartier, 1997).

Para que o livro digital possa ser acessado, são necessários um aparelho (hardware) e um programa ${ }^{9}$ (software). Estes figuram decisivamente para a boa recepção do conteúdo da obra, porém muitas vezes limitam as possibilidades que poderiam ser exploradas na diagramação efetivada na organização do texto e, ainda, nas possíveis interatividades disponibilizadas ao leitor através do artefato digital. Ao se observar as especificidades de cada aparelho e software, é necessário relativizar suas características materiais com seu uso, levando em consideração onde será usado, os aparatos necessários para assessorar a utilização do aparelho etc. (DOURISH, 2004). ${ }^{10}$

7 Disponível em: http://hdl.handle.net/10183/97246.

8 Chartier, Roger (Org.). Práticas de leitura. São Paulo: Liberdade, 1996.

9 No caso dos aparelhos móveis, a mídia convencionou chamar os programas do mesmo de aplicativos (apps). Em virtude de sua igual função, neste trabalho os termos "programa", "software" e "aplicativo" serão tratados como sinônimos.

10 Este trabalho enfoca o artefato, diferente de Dourish, que traz uma abordagem mais relacionada aos usos do mesmo. Em trabalhos futuros, pensa-se em trazer um olhar mais voltado para a utilização dos livros digitais, alinhado à perspectiva de Dourish. 
As características não verbais que podem ser atribuídas ao texto auxiliam o leitor a se preparar para a leitura, inserindo-o "sobre um sistema de expectativa" e inscrevendo-o "numa trajetória previsível" (VIgner, 1988, ${ }^{11}$ p. 33 apud GRUSZYNSKI, 2007, p. 130), onde poderá confirmar suas hipóteses ou ser surpreendido por uma abordagem diferenciada. A apresentação do texto "pode contribuir para uma ampliação do repertório do leitor e/ou comprometer a percepção da mensagem" (GruSZYNSKI, 2007, p. 130). Por consequência, pressupõe-se que, a cada nova reedição, formato ou versão de um mesmo texto, a obra não será a mesma, pois carregará outros significados (CHARTIER, 1999). Gumbrecht (1998, p. 359) também menciona a possibilidade do leitor atentar para "as qualidades sensoriais em que os significantes da linguagem transcendem sua função tradicional de transmitir significado", ${ }^{12}$ sugerindo a atenção ao layout e ao próprio ritmo imposto pelo texto, que se faz presente mesmo em uma leitura silenciosa.

No caso do livro impresso, o processo de produção de uma edição culmina em um objeto com cópias consideradas idênticas; portanto todos os leitores de uma ou outra edição terão acesso ao "mesmo" livro. Já ao pensar no livro digital, o próprio equipamento do leitor, que permitirá a visualização e interação com o exemplar, por possuir características específicas, pode apresentar-se de forma diferente a cada leitor, conforme o aparelho que este utilizar. Além disso, Landow (2006) mostrou que depois da passagem do manuscrito para o livro, a mudança para o meio digital foi o grande acontecimento na sua história. $\mathrm{O}$ autor separou esses dois momentos em dois grandes grupos: de "texto rígido" (hard text) e de "texto flexível" (soft text). O primeiro foi categorizado como rígido e fixo pelas características do papel e da tinta, já que depois de impressos ou escritos, o texto não poderá mais ser modificado. E, o segundo, tratou como flexível, já se referindo ao digital, pois como sua informação é feita por códigos que podem ser alterados. Ou seja, ao mesmo tempo que possibilita a multiplicidade da impressão, não traz a confiabilidade e estabilidade dos textos em papel (LANDOw, 2006).

Sabe-se que uma nova tecnologia emerge de um contexto cultural, a partir do remodelamento (refashion) de outra mídia e é incorporada no mesmo contexto ou em contextos similares, modificando também as mídias existentes anteriormente (Bolter; Grusin, 200o). Para referir-se a esse fenômeno, Bolter e Grusin (2000) criaram o conceito de remediação (remediation) para falar justamente dessa lógica formal que uma nova mídia se apropria das anteriores, repetindo-as ou alterandoas. Para os autores, a mescla dessas mídias - da nova com a antiga - pode acontecer de diferentes formas, dando-se ênfase à mídia antiga, buscando deixar a nova mídia mais transparente, buscando um contato direto com a mídia anterior através da nova, o que seria chamado de imediação (immediacy); ou enfatizando as características da nova mídia, o que eles definiram como hipermediação (hipermediacy).

\footnotetext{
${ }^{11}$ VIGNER, Gerard. Inter-textualidade, norma e legibilidade. In: GALVES, Charlotte et al (Ed.). O texto: escrita e leitura. Campinas, SP: Pontes: 1988, p. 31-31.

12 Citação original: [...] because it directed the reader's attention to sensual qualities in which the signifiers of language transcend their traditional function of conveying meaning.
} 
Muitas vezes a imediação e a hipermediação estão presentes no mesmo artefato, alternando de acordo com a observação do usuário. No caso do livro digital visto no tablet, ora a atenção pode ser despertada pela simulação do livro impresso (imediação), ora pelo próprio aparelho que promove essa visualização e que também promove a percepção de materialidade, diferente do livro impresso (hipermediação).

Dadico (2011) aplicou o "método fisiognômico", desenvolvido e utilizado por Theodor Adorno ${ }^{13}$ para analisar o rádio, a fim de observar o livro impresso. A autora tentou observar a materialidade do livro, ou seja, as características iminentes ao suporte e não ao seu conteúdo, chegando a cinco particularidades: "a) a ilusão de proximidade; b) a conservação temporal; c) a ubiquidade relativa; d) a semipadronização; e) a unidade portabilidade-fluidez" (DADICO, 2011, p. 63); as quais serão explicadas nos próximos parágrafos.

Dadico (2011) afirmou que o leitor se inclina a sentir uma ilusão de proximidade do autor, através do livro, como se este, por intermédio daquele texto, se dirigisse a ele, o leitor, como indivíduo. Contraditoriamente essa ilusão é intensificada "pelo caráter não imediato do livro" (DADICo, 2011, p. 64, grifo da autora), já que, ao ler, o leitor atualiza aquele conteúdo, trazendo para o seu presente o que foi escrito no passado. Vale lembrar que principalmente no caso do livro impresso, o texto sempre terá sido escrito em um tempo consideravelmente anterior ao processamento da leitura, tendo em vista todo seu processo de revisão, produção e distribuição.

A ubiquidade relativa estaria relacionada ao fato de que, apesar de existirem vários exemplares de um mesmo livro, estes não seriam consumidos em um mesmo momento por diversos leitores. Ao mencionar a semi-padronização, a autora referiu-se tanto à produção do livro quanto à ampliação do público para o best-seller.

Ao tratar da condição unidade portabilidade-fluidez, Dadico (2011) reuniu os atributos de portabilidade, que é relacionado ao livro, e fluidez, que considera inerente à sua leitura. Ao agregar esta última característica, ela pensou mais especificamente no modelo de leitura distraída ${ }^{14}$ o qual considerou bastante emblemático no cenário atual. A portabilidade estaria relacionada à possibilidade de o leitor levar um livro de um lugar para outro e a fluidez ao controle de seu ritmo de leitura.

A partir das propriedades do papel, da tinta, da qualidade da encadernação etc., o livro impresso possui uma conservação temporal. Essa "imutabilidade" é considerada por Dadico (2011) como uma das particularidades que confere autoridade ao livro, já que o autoriza a servir como testemunho material de um discurso de seu autor, que pode então ser conservado intacto no tempo.

Nielsen (1999, p. 4) percebeu como uma desvantagem da publicação impressa a incapacidade "de reimprimir e distribuir imediatamente este livro caso seja preciso

\footnotetext{
${ }_{13}$ Adorno, Theodor. Current of music: elements of a radio theory. Frankfurt: Suhrkamp, 2006.

${ }^{14}$ Leitura sem concentração, na qual o leitor pula trechos (DADICO, 2011).
} 
atualizar qualquer erro ou avanços tecnológicos". Tal observação corrobora com o aspecto da conservação temporal, apontada por Dadico (2011). O meio digital, com sua possibilidade de atualização, pode induzir a uma publicação mais rápida, tendo em vista que à medida que as incorreções vão sendo percebidas, podem ser alteradas e atualizadas mais facilmente. No entanto, outra faceta do setor editorial que emergiu nos últimos anos foi a impressão sob demanda, onde o arquivo é armazenado digitalmente para ser impresso e encadernado quando solicitado pelo leitor, reconfigurando a possibilidade de correções e atualizações no meio impresso.

Diante dessa possibilidade de atualização tanto no impresso como no digital, o confronto entre estabilidade $v s$. instabilidade e fixidez $v$ s. fluidez pode ocorrer em qualquer instância, inclusive nos documentos em papel. Sendo assim, deve-se seguir um padrão convencionado que estará ligado ao ritmo de fixidez e de fluidez. $\mathrm{O}$ documento em papel pode deixar de ser validado em função da expedição de outro mais novo, mas se deve lembrar que o papel original, mesmo depois de alterado, provavelmente deixará rastros do seu conteúdo, como um palimpsesto. O mesmo não ocorre com o arquivo digital, uma vez que, a menos que se tome um cuidado de registrar que o mesmo foi alterado, parecerá sempre um novo arquivo.

Roger Chartier (1997) questionou as ações contraditórias impostas pela existência do objeto livro, visto que se, por um lado, o leitor possui uma série de obrigações e instruções para ler "da forma correta" aquele conteúdo, por outro, ele pode subverter aquilo que está escrito ou que é instruído, lendo por entre as linhas. Dadico (2011) tratou dessa autonomia do leitor utilizando o termo fluidez e com essa palavra a autora se refere ao ritmo da leitura, ditado por aquele que está lendo. Para Chartier (1997), o livro sempre tenta instaurar uma ordem em algum sentido uma ordem de como deve ser entendido, de sua decifração ou aquela determinada por quem encomendou a obra -, "No entanto, essa ordem [...] não detém o poder absoluto para anular a liberdade dos leitores" (ChARTIER, 1997, p. 6). Sendo assim, o livro impõe uma ordem, que pode ser seguida ou não pelo seu leitor, quer seja no meio impresso ou no meio digital. No impresso essa sequência é induzida pela paginação e pelo sumário, no meio digital pode ser explorada de outras formas.

\section{O livro digital e suas materialidades sobrepostas}

Com a inserção do livro digital, Landow (2007) afirmou ser a primeira vez, dentro de muito tempo, que foi possível assistir uma grande inovação tecnológica na história do livro e, com isso, tornou-se possível desassociar a ideia desse artefato do formato do códex. Bastos (2005, p. 129) observou que as metáforas, representações e relações de similaridade impedem "a investigação de novas possibilidades oferecidas pela digitalização, na medida em que ainda se prende a paradigmas analógicos" (BASTOS, 2005, p. 129). Diante das novas tecnologias, a tensão entre a convenção e a inovação está presente no livro digital, observando que se abre um leque de possibilidades a serem exploradas que não seriam possíveis no papel. 
No entanto, ao se buscarem esses recursos, corre-se o risco de sair do padrão estabelecido e ir em direção a um novo artefato, o qual já não mais se reconhece como sendo um livro e sim como outra forma de contar uma história ou de apreender um conteúdo. Bastos (2005) propôs justamente a criação de uma nova escrita nas mídias digitais, a qual se dividiria nos termos e-scrita e ex-crita. A primeira seria a escrita eletrônica: "o termo e-scrita atribui uma qualidade ao substantivo escrita; não muda sua essência, apenas indica que a escrita em computador tem atributos que não tinha até então" (BASTOS, 2005, p. 95). Já o termo ex-crita, seria marcado pela tensão entre a possibilidade de escrever de outra forma nas mídias digitais e o apego aos formatos culturalmente aceitos; assim, o termo ex-crita indicaria a escrita que não é mais, mas que seria marcada pelo que foi. Baseado na reflexão de Bastos (2005) pode-se pensar na possibilidade de serem exploradas diferentes concretizações do livro no meio digital, tanto respeitando as heranças traçadas previamente pelo impresso, quanto criando algo totalmente novo.

Meyers (2011) se propôs a pensar nas possibilidades que o meio digital tem para inovar o livro e um dos elementos ao qual dedicou sua atenção foi o sumário, como um dos representantes da ordem de leitura sugerida pelo livro impresso (Bolter, 2001; HeNDEL, 2006). Ao se pensar na organização de temas, o sistema digital pode acomodar tanto um formato tradicional de índice - que foi o que obteve maior sucesso na organização e indexação no meio impresso - bem como explorar outras formas para apresentação de conteúdo (Meyers, 2011; WeInberger, 2007). Desse modo é evidenciado o caráter híbrido (impresso e digital) que o livro pode adquirir.

O leitor recebe um livro impresso com uma forma fixa, onde o seu exemplar é praticamente igual a todos os outros daquela edição e, antes de chegar às suas mãos, ele passou por uma série de processos e tomadas de decisão para se configurar da forma que se apresenta. A configuração do livro digital que chegará ao leitor depende de fatores decididos por ele mesmo, sendo necessário pensar em qual aparelho e software o livro será acessado. No livro digital não existe um formato padrão que possa ser encaminhado a todas as lojas virtuais, uma vez que cada empresa exige uma finalização de arquivo diferenciada, cada aparelho possui configurações específicas e o conteúdo que pode funcionar muito bem em um, pode simplesmente não abrir em outro. Nada disso, entretanto, elimina o processo editorial de tomadas de decisão, que existe no livro digital da mesma forma que no impresso. Portanto, assim como cada elemento do impresso é analisado e ponderado, como, por exemplo, se o livro será de capa dura ou não, qual o tipo de papel que será utilizado, em quantas cores será impresso e, que custos essas escolhas agregarão ao produto final; na produção digital também são avaliados os recursos e formatações a serem utilizados e o custo/benefício de cada opção. Por não ter uma forma final fixa, as diferentes camadas de significado somadas às ferramentas que o leitor dispõe devem ser levadas em consideração no momento do projeto desse conteúdo, uma vez que, essas escolhas podem definir quem terá ou não acesso ao mesmo. 
Para compreender melhor o livro digital é necessário entender como esses elementos que o compõem se relacionam e de que forma um interfere sobre o outro. Desse modo, optou-se por uma abordagem didática tentando analisar cada elemento separadamente; contudo, vale dizer que é impossível isolá-los completamente já que são sobrepostos no artefato estudado. As possibilidades de recursos que podem ser exploradas no livro, dependem das restrições impostas pelo software reader, que, por sua vez, se limita a utilizar o que é possível dentro daquele equipamento de leitura. Neste trabalho, essas três partes serão chamadas de conteúdo, software e hardware e compreendidas de forma próxima ao esquema exibido na Figura 1.

Esquema proposto para compreensão do e-book

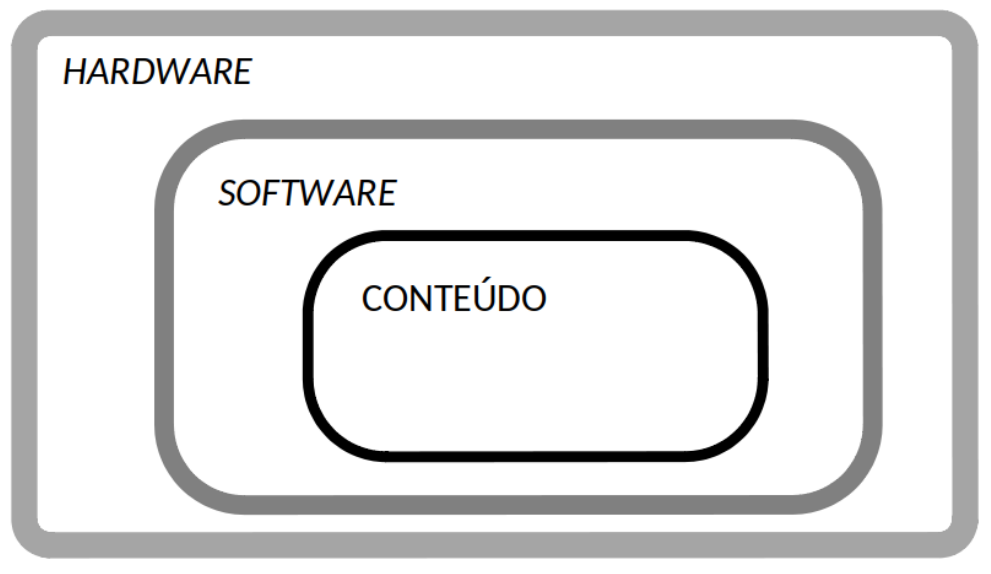

FIGURA 1 - Relação entre o hardware, software e conteúdo que resultam em um livro digital. Fonte: a autora.

Basicamente, existem três tipos de livros digitais: os disponibilizados online por intermédio do navegador, os que são baixados para o computador e acessados através de um software ou aplicativo de leitura e os que são o próprio software/aplicativo instalado no sistema operacional do aparelho. Nos dois primeiros é possível separar os elementos de acordo com o esquema apresentado (hardware, software e conteúdo); no último, as camadas software e conteúdo são mescladas.

Neste esquema a palavra hardware está sendo usada para denominar o aparelho que é utilizado para a leitura do livro. Atualmente o livro digital pode ser lido em diversos tipos de equipamentos, tais quais computadores de mesa, notebooks, netbooks, tablets, palmtops, smartphones, e-readers etc. Em cada tipo de equipamento, a relação do leitor com a leitura será diferente. Por exemplo, em um computador de mesa o leitor será impedido de trocar de lugar durante a leitura e, para avançar no texto, terá que usar o teclado, o clique do mouse ou, ainda, o scroll, com um tablet ele pode se movimentar e se posicionar de modo mais semelhante ao que faria com um livro. Cada aparelho tem características específicas que podem ser vistas como vantagens para um leitor e desvantagens para outro, portanto cabe 
a cada pessoa testar e perceber ao qual, ou aos quais, dentre os existentes, ela se adapta melhor em cada situação de leitura (BAR et. al, 2007).

Para Procópio (2010, p. 45), "o reader ${ }^{15}$ é o software ou o aplicativo desenvolvido para auxiliar na leitura de livros" nos diversos aparelhos passíveis de serem utilizados para essa função, desde computadores de mesa a smartphones. Normalmente os softwares são gratuitos e especialmente programados para leitura, trazendo ferramentas específicas para auxiliar essa atividade. O software, dentro das possibilidades do hardware, delimita as ações que o leitor pode fazer no livro digital. Podese dizer que muitos recursos imitam o que pode ser feito com o livro impresso, porém alguns são menos interativos do que o texto no papel, já que a única ação que determinado software ou o arquivo permitem é o avanço das páginas e o aumento da imagem (zoom) para uma melhor visualização de algum detalhe, não possibilitando, entretanto, marcações, anotações e inclusive, se visualizados em um computador, não podem nem ser carregados facilmente de um lugar para outro.

Como foi comentado, o sentido da leitura é construído com base no que é sugerido no texto e no contexto, ou seja, nas palavras do autor e no arranjo visual arquitetado pelo designer (HENDEL, 2006; CHARTIER, 1997; GrUSZYNSKI, 2007). No meio digital, um terceiro ponto influencia na contextualização: o tipo de formato escolhido para disponibilizar o $e$-book, observando que cada um oferece uma gama de diferente de recursos. $\mathrm{O}$ arquivo digital é constituído de linguagens de códigos que se assemelham às utilizadas na criação de sites, como o HTML, XHTML, XML etc. Assim, o arquivo do e-book será criado e posteriormente, empacotado e transformado em EPUB. Esse processo de empacotamento é semelhante ao que acontece a um arquivo zIP (GUERRATO, 2012). Finalmente, antes de ser disponibilizado ao público, poderá passar por uma criptografia para ser administrado através de uma ferramenta DRM, com a finalidade de evitar a pirataria.

Ao pensar sobre o conteúdo/livro, percebe-se que este pode ser dividido em três camadas, que seriam constituídas das informações "puras" (texto); ${ }^{16}$ da configuração visual, na qual esse conteúdo é organizado (design); e do tipo de arquivo que será finalizado (formato). Dessa forma, a parte de conteúdo, inserida na FigURA 1, seria, ainda, composta pela tríade: texto, formato e design (FIgURA 2).

O texto de um autor pode ser apresentado com diversas abordagens, podendo constituir-se apenas de texto, de texto e imagem, de texto e animações, de texto e música... Cada formatação agregará outros sentidos ao conteúdo, e pensando exclusivamente em um livro, este poderá ser publicado em papel ou no formato digital. Muitas vezes será possível encontrar de distintas formas, inclusive no meio impresso. Um exemplo desta ocorrência seria um livro com uma edição de bolso e outra de luxo, um podendo vir acompanhado de imagens e o outro não, um ser

\footnotetext{
15 Alguns autores utilizam o termo reader (leitor) para referirem-se aos softwares específicos para leitura.

16 Neste caso o texto é utilizado no sentido semiótico, englobando as informações caracterizadas por diferentes linguagens multimídia que serão organizadas no design.
} 
Esquema proposto para compreensão do e-book

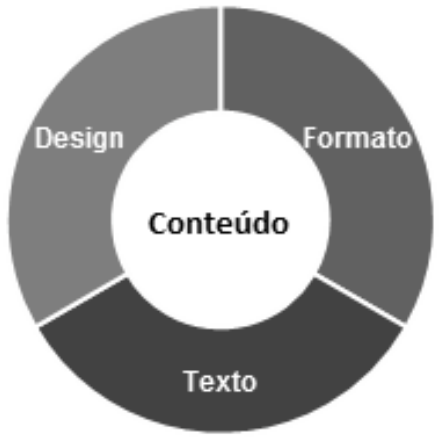

FIGURA 2 - Elementos que formam o conteúdo do livro digital. Fonte: a autora.

colorido e o outro em preto e branco. Dessa forma, pode-se concluir que a publicação em diferentes formatos com a finalidade de abranger públicos diferentes, não é uma novidade lançada no livro digital e, sim, uma prática comum no cenário editorial. Vale dizer que, nesses casos, ao mesmo tempo em que o conteúdo exposto é o mesmo, ele também é diferente, pois existem camadas distintas de informação agregadas a este (CHARTIER, 1999; LyONS, 1999).

Um fato interessante é que "a norma padrão do ISBN, ISO 2108, sempre solicita que as diferentes formas de um produto de uma publicação, quando disponibilizadas separadamente, tenham números de ISBN separados” (ISBN, 2010, online). Quando a norma foi revisada em 2005, chegaram à conclusão que as mesmas regras deveriam ser aplicadas às publicações digitais. Logo, a nova norma explica: "cada formato diferente de uma publicação eletrônica [...] que seja publicada e disponibilizada separadamente deverá ter um número de ISBN separado" (ISBN, 2010, online). Portanto, a Agência Internacional do ISBN reitera a ideia de que cada conteúdo apresentado de forma diferenciada ou em um formato diferente caracteriza uma nova obra.

\section{Caracterização dos livros digitais}

Partindo-se da ideia de que o livro é um objeto com características flexíveis, propõe-se uma série de princípios que juntos caracterizam esse tipo de publicação, independente de ela ser digital ou impressa. As particularidades atribuídas aos livros podem ser divididas em dois grupos: um deles agregando aquelas peculiaridades que sempre se mantêm em todas as produções editoriais dessa categoria e o outro abrangendo aquelas propriedades que comumente aparecem associadas ao livro, mas que não estão presentes em todas as publicações. Desse modo, com base neste estudo, consideramos que o livro pode ser caracterizado obrigatoriamente como uma publicação não-periódica que possui identidade própria (unidade completa em si), mantendo-se inalterada (caracterizando uma edição), estando dis- 
ponível para ser adquirida e/ou acessada por um grupo de pessoas ou instituição, indexada com um número ISBN e metadados sobre a mesma e que possui um elemento declaratório que a caracterize como livro (fich catalográfica ou outra indicação textual). E, ainda, pode-se acrescentar que, é possível que existam conteúdos extras junto ao livro, fazendo a ressalva de que devem ser tratados como complementação do conteúdo principal, observando que sua inexistência não deve prejudicar a compreensão da leitura. Como exemplo desses conteúdos extras, podemos citar: conteúdos com espaço para completar; atividades lúdicas ou de aprendizagem; textos complementares; hipertextos que direcionem o leitor para conteúdos incluídos no livro ou fora do mesmo.

Levando-se em conta os parâmetros estabelecidos para que um artefato seja aceito como livro, deve-se dizer que a presença de algumas obras dentro da amostra analisada poderia ser questionada, já que suas características as situam na fronteira da definição, uma vez que se detectou a falta de alguns elementos "obrigatórios" como o ISBN ou os metadados sobre as obras. Entretanto, o critério de seleção foi justamente artefatos que estivessem sendo nomeados como "livros digitais", mesmo que, como ocorreu em alguns casos, fossem assim chamados sem necessariamente se autoafirmarem como tal ou sem haver uma preocupação por parte dos seus produtores com o rótulo que a produção receberia.

A partir da amostra dos e-books construída, pôde-se perceber segmentos com características bem definidas e que diferem entre si em sua formatação e na exploração dos recursos digitais. Ao observar a nomenclatura utilizada no meio impresso, verificou-se que o termo "livro" é utilizado de maneira geral, e quando a obra tem alguma especificidade é acrescentado um termo a este, caracterizandoo dentro de um grupo de particularidades, como, por exemplo: os livros infantis, livros pop-up, livros de bolso etc. A mesma relação pode ser feita com os livros digitais. No âmbito deste trabalho é possível sugerir formas julgadas pertinentes para identificar os grupos referidos. A intenção não é, evidentemente, cunhar um termo e exigir que todos passem a utilizá-lo, mas apenas apontar uma formulação que, conforme a pesquisa, responde à história e à realidade empírica.

O termo livro digital pode ser utilizado como um sinônimo de $e$-book e livro eletrônico, abrangendo todas as possibilidades de publicação no meio digital que possam ser caracterizadas como livro, seguindo os aspectos propostos neste estudo. De acordo com as características percebidas na análise da amostra, foram distinguidos os tipos de $e$-book descritos a seguir.

O livro digital customizável permite que a configuração visual do texto se adapte de acordo com o tamanho da tela do equipamento do leitor. Costuma ser acessado através de softwares readers, os quais normalmente possuem facilidades para atender à atividade de leitura (como dicionário embutido, busca de palavras ou índice hipertextual). A principal característica desse tipo de $e$-book é a possibilidade de customização oferecida pelo software, como aumentar o tamanho da letra, as cores e a tipografia. Para referir-se a esse tipo de arquivo foram encontrados os termos: 
"líquido" e "texto corrido"; o primeiro fazendo analogia à característica da substância líquida que adquire o formato de seu recipiente, e o segundo enfatizando a independência do texto com relação à sua configuração visual, já que a informação textual altera a sua disposição na tela, diferente dos textos com layout fixo.

O livro digital com layout fixo é aquele cuja configuração visual não se altera em função do aparelho utilizado e das preferências do leitor. O arquivo pode ser acessado em um software reader, bem como através de um aplicativo a ser instalado diretamente no sistema operacional. O termo layout fixo foi visto em sites, com o intuito de caracterizar o arquivo EPUB com layout fixo, no entanto, nesta proposta de estudo, o termo serviria para qualquer tipo de arquivo que tivesse a especificidade de manter sempre a mesma diagramação, como PDF, EPUB com layout fixo, aplicativos etc. Em alguns casos existe a possibilidade de ativar-se o zoom na imagem e no texto, mas não há uma reacomodação das palavras, como ocorre com o livro digital customizável.

O livro PDF estaria classificado dentro do grupo de e-books com layout fixo. Contudo, é dado um destaque a essa extensão de arquivo, em função do formato PDF ter sido aperfeiçoado ao longo dos últimos 20 anos, sendo um tipo de arquivo conhecido e indicado pelo ISO como um formato padrão para troca de documentos. Portanto, a indicação do mesmo dentro desse grupo pode indicar a característica do layout fixo e também ser mais específico quanto à sua formatação. Optou-se por excluir o termo "digital" desse grupo para evitar o pleonasmo, posto que se o livro é PDF, ele só pode ser digital.

O livro digitalizado é aquele resultante da digitalização de um volume impresso. Este grupo também poderia se inserir dentro dos livros digitais com layout fixo, mas a peculiaridade que possui de manter a diagramação somado ao fato de ser gerado a partir do livro impresso e preservar a configuração visual do livro que originou, é uma característica a ser especialmente considerada. Mais forte do que simplesmente manter o layout inalterado, abarca um grande número de publicações, merecendo, por isto, uma categoria diferenciada. Normalmente esse tipo de livro é constituído de um arquivo PDF. Neste grupo também foi excluído o termo "digital", para evitar, além do pleonasmo, a aliteração de "digital digitalizado". Em decorrência disso, dá-se preferência aos termos livro digitalizado e e-book digitalizado.

É necessário que se faça um parêntese antes de apresentar os livros digitais multimídia e interativos. Para caracterizar os e-books que oferecem esses recursos, normalmente é utilizado o termo "enhanced book", que seria traduzido por livro aprimorado, ou "livro aplicativo". O ponto negativo da primeira expressão é a indução ao julgamento de que esse livro seria melhor do que aquele que contém apenas texto e imagem estática, o que pode não ser verdade. No entanto, é possível afirmar que esse tipo de livro oferece mais recursos do que os outros, independente de ser melhor ou não. A referência à utilização de "livro aplicativo" faz relação com o formato que normalmente essas obras são distribuídas - como aplicativos mas, na verdade, não necessariamente um livro interativo ou multimídia será um 
aplicativo. Para diferenciar a versão do e-book que se faz acompanhar de vídeos e sons e que não é um aplicativo, das demais versões, a Companhia das Letras optou por utilizar o termo "edição especial". Dessa forma, procurou mostrar ao leitor que esse conteúdo possuía "algo a mais" em relação aos outros livros digitais, mas não especificava o que seria esse diferencial.

Neste tipo de livro existem dois grupos de recursos que podem vir juntos ou não: a multimídia e a interatividade. No caso da utilização de áudio ou vídeo, a multimídia se destaca mais do que a interatividade, observando-se, neste caso, que a interatividade estaria relacionada à possibilidade de serem acionados o vídeo, a pausa etc., sendo esta uma ação menos significativa que a observação de um vídeo. Contudo, existem casos em que a interatividade pode ser tão significativa quanto aos recursos multimidiáticos que acompanham a leitura, como animação, som etc.

Em função disso, o termo multimídia ou interativo é considerado o mais adequado para identificar esse tipo de livro digital, levando-se em consideração qual dessas possibilidades se sobressai mais na narrativa, sem esquecer, que os recursos interativos destacados nessa definição são associados ao conteúdo e não àqueles atribuídos referentes aos softwares de leitura. No caso dos livros aplicativos, pode-se associar o rótulo interatividade aos recursos que vão além dos que estão envolvidos com a atividade de leitura, possibilitando, assim, diferenciar os tipos de ações. Assim é possível ter livros digitais multimídia, os quais disponibilizam além do texto, imagens animadas e sons, podendo exibir imagens estáticas ou não; e livros digitais interativos, os quais possibilitam ao leitor realizar ações sobre o livro, manipulando e ativando alterações na cena, na história, nos personagens; ações estas diferentes das relacionadas à leitura.

Vale ressaltar ainda que muitas vezes as características podem ser somadas, como foi detalhado na diferenciação entre os e-books interativos e multimídia, podendo existir ainda um livro digital que além dessas duas características também seja customizável, por exemplo. Quando ocorrer essa situação, pode-se utilizar mais de um termo para caracterizar o livro digital, mas é preferível, para evitar uma nomenclatura mais longa, que seja eleito o recurso mais significativo.

Nessas classificações não foram incluídas as possibilidades de interação entre os leitores, observando-se que essa característica seria mais relacionada ao uso do artefato e não à constituição do mesmo. Esta referida interação poderá ser adicionada a qualquer uma das categorias citadas, relacionando-se melhor com a plataforma que subsidia o acesso ao livro e proporciona essa conexão entre os diferentes atores, do que com o arquivo do artefato.

Por fim, em um apanhado sintético para maior clareza, as caracterizações apresentadas podem ser resumidas da seguinte maneira: os livros digitais podem ser chamados de livros eletrônicos ou e-books. São constituídos de um conteúdo digital com as mesmas características de um livro (seguindo os parâmetros apontados 
aqui) e podem explorar, além do texto e da imagem, recursos da mídia digital, tais como som, vídeo e animação. Existem diversos tipos de livros digitais, tais como:

1. livro digital customizável: livro digital que permite que a configuração visual do texto se adapte de acordo com o equipamento e preferências do leitor. Costuma ser acessado através de softwares readers, os quais normalmente possibilitam aumentar o tamanho da letra, as cores e a tipografia;

2. livro digital layout fixo: livro digital cujo layout não se altera em função do aparelho e preferências do leitor;

3. livro PDF: livro digital com layout fixo em formato PDF;

4. livro digitalizado: livro digital criado a partir da digitalização de um livro impresso;

5. livro digital multimídia: livro digital que apresenta, além do texto ou imagem estática, vídeos, animações e sons;

6. livro digital interativo: livro digital com conteúdos que exigem a ação do leitor para acioná-los ou manipulá-los, diferente das ações associadas à leitura.

\section{Considerações finais}

O livro digital é um artefato interessante, pois ao mesmo tempo em que ele é recente e passível de constantes transformações, também é repleto de convenções e tradições provindas do livro impresso. A história do $e$-book se entrelaça com a história do livro impresso e da própria escrita. Através do resgate histórico trazido neste artigo, foram apontadas mudanças ocorridas na materialidade do livro, ora na sua forma como objeto, ora em sua configuração visual. A cada mudança, novos hábitos e gestos acabaram sendo criados e associados à leitura.

O meio digital apresenta características opostas ao impresso, que é fixo e "imutável". A tela de um aparelho eletrônico é útil justamente por sua capacidade de transformação, posto que se modifica instantaneamente a partir da ação do usuário, mostrando-lhe o resultado de sua ação, que pode ter sido informada à máquina através do teclado, mouse ou do toque, por exemplo. É justamente esta capacidade da tela de transformar-se rapidamente que permite o avanço da leitura no livro digital, onde cada página representada desaparece para dar visibilidade à próxima.

A configuração de um livro, impresso ou digital, subsidia um conhecimento sobre o contexto em que foi produzido, exibindo os modos de produção e expressão da época. Para citar um exemplo, se ocorrer a atualização da ortografia de uma obra e o arquivo anterior for apagado, então se perderá a forma de escrita de outrora. Portanto, no caso de haver necessidade de proceder a alguma alteração no livro digital, é importante que se leve em conta esse conhecimento já divulgado e adquirido pelas pessoas que o leram. Por este motivo, é também importante que se 
estabeleça uma norma para executar a referida alteração, definindo quem teria autoridade para desvalidar um texto publicado e de que forma isso deveria ser feito.

Nos materiais impressos também ocorrem essas normatizações: estabeleceu-se que para um documento ser desvalidado, outro deve ser emitido em seu lugar, mas, via de regra, o anterior não deixa de existir ao ser tornada pública uma versão mais atual. Já no meio digital, deve haver um cuidado maior para um arquivo não sobrescrever o outro para que, ao alterá-lo, não haja a perda total do arquivo antigo, posto que se a cópia anterior desaparecer não será possível se estabelecer a comparação de exemplares, nem verificar informações que vão além daquelas transmitidas pelo autor.

Por fim, vale dizer que com este trabalho se buscou uma aproximação destes artefatos que estão sendo produzidos sob o rótulo de livro digital, tentando entender suas características e peculiaridades a partir da sua complexa materialidade no meio digital. $\mathrm{O} e$-book ainda está sendo inserido na vida dos leitores, escritores, editores, designers etc. e ainda existem inúmeras possibilidades a serem exploradas, tanto no próprio artefato quanto na pesquisa sobre o mesmo.

\section{Referências}

Bar, François; Pisani, Francis; Weber, Matthew. Mobile technology appropriation in a distant mirror: baroque infiltration, creolization and cannibalism. In: Seminario sobre Desarrollo Económico, Desarrollo Social y Comunicaciones Móviles en América Latina. Fundación Telefónica. Buenos Aires, 2007.

Bardin, Laurence. Análise de Conteúdo. Lisboa: Edições 7o, 2011.

Bastos, Marcus Vinicius Fainer. Ex-Crever? literatura, linguagem, tecnologia. 2005. Tese (Programa Comunicação e Semiótica) da Pontífica Universidade Católica de São Paulo. Orientador(es): Maria Lucia Santaella.

Bolter, J. David; Grusin, Richard. Remediation: Understanding New media. Cambridge: The MIT Press, 2000.

Chartier, Roger. A Ordem dos Livros. Lisboa: Vega, 1997.

Chartier, Roger. A aventura do livro: do leitor ao navegador. São Paulo: Editora UNESP/Imprensa Oficial do Estado, 1999.

DAdico, Luciana. Constelações do livro: fisiognomia e experiências de leitura. 2011. 221p. Tese (Doutorado) - Instituto de Psicologia, Universidade de São Paulo, 2011. Orientador(es): Iray Carone

Dourish, P. Social Computing. In: Where the Action Is: the foundations of embodied interaction. Cambridge: The MIT Press, 2004. pp. 55-97. 
Fragoso, Suely; Recuero, Raquel; Amaral, Adriana. Métodos de Pesquisa para Internet. Ed. Sulina: Porto Alegre, 2012.

Gruszynski, Ana Cláudia. A imagem da palavra: retórica tipográfica na pósmodernidade. Teresópolis, RJ: Novas Ideias, 2007.

Guerrato, Dani. ePub: Aprenda a criar um livro digital. In: Tabless. 2012. Disponível em: http://tableless.com.br/epub-aprenda-a-criar-um-livro-digital/\#. UjhNt8ZwrdQ. Acesso em: 5 jan. 2014.

Gumbrecht, H. U. Perception versus Experience. In: Lenoir, T. (org.). Inscribing Science, Scientific Texts and the Materiality of Communication. Stanford: Stanford University Press, 1998. pp. 351-364.

Hendel, Richard. O design do Livro. $2^{\text {a }}$ ed. Cotia: Ateliê Editorial, 2006. 224 p.

ISBN, Agência Brasileira do ISBN. Publicações eletrônicas. 2010. Disponível em: http://www.isbn.bn.br/website/publicacoes-eletronicas. Acesso em: 3 jan. 2014.

Landow, George P. Hipertext 3.o: Critical Theory and New Media in an Era of Globalization. 3 ed. Baltimore: The Johns Hopkins University Press, 2006.

Lyons, Martyn. A palavra impressa: história da leitura no século XIX. Rio de Janeiro: Casa da Palavra, 1999.

Meyers, Peter. Breaking the page - Preview edition. O'Reilly Media. 2011.

Nielsen, Jakob. Projetando Websites. $1^{\text {a }}$ ed. São Paulo: Campus, 1999.

Patton, Michael Q. Qualitative research \& Evaluation Methods. $3^{\text {a }}$ ed. London: Sage, 2002

Procópio, Ednei. O livro na era digital: o Mercado editorial e as mídias digitais. São Paulo: Giz Editorial, 2010.

Sehn, Thaís Cristina Martino; Fragoso, Suely. Um retrato dos livros digitais: desenvolvimento de instrumental metodológico para estudo empírico, p. 3129-3141. In: Anais do $11^{\circ}$ Congresso Brasileiro de Pesquisa e Desenvolvimento em Design [= Blucher Design Proceedings, v. 1, n. 4]. São Paulo: Blucher, 2014. DOI: 10.5151/designproped-oo679.

SeHn, Thaís Cristina Martino. As possíveis configurações do livro nos suportes digitais. 2014. Dissertação (Mestrado em Comunicação e Informação) - Faculdade de Biblioteconomia e Comunicação, Universidade Federal do Rio Grande do Sul. Orientador: Suely Fragoso. Disponível em: https://lume.ufrgs.br/handle/10183/97246. Acesso em: 5 mar. 2018.

Weinberger, David. A nova desordem digital: os novos princípios que estão reinventando os negócios, a educação, a política, a ciência e a cultura. Rio de Janeiro: Elsevier; Campus, 2007. 
Recebido em o5 de julho de 2018.

Aprovado em 23 de fevereiro de 2019.

\section{Resumo/Abstract/Resumen}

\section{A caracterização dos livros digitais a partir de sua materialidade}

\section{Thaís Cristina Martino Sehn, Suely Fragoso, José Luís Farinatti Aymone}

O objetivo desta pesquisa foi mapear os artefatos que são atualmente denominados "livros digitais", caracterizando-os a partir do cruzamento dos recursos próprios do meio digital com as principais especificidades dos livros impressos. A metodologia utilizada abrangeu revisão bibliográfica e observação do objeto de estudo. Neste estudo o livro foi percebido como um artefato com propriedades flexíveis, decidindo-se, por isto, propor uma série de princípios que, juntos, possam ser utilizados para caracterizar esse tipo de publicação, independente de ela ser digital ou impressa. Logo, chegou-se a conclusão de que o e-book é um conteúdo digital com as mesmas características de um livro e que pode explorar, além do texto e da imagem, recursos da mídia digital, tais como interatividade, som, vídeo e animação. Através das características predominantes dos artefatos analisados, foram identificados os seguintes tipos de livros digitais: customizável, PDF, digitalizado, multimídia e interativo.

Palavras-chave: design, e-book, livro eletrônico, remediação.

\section{The Characterization of Digital Books Based on Their Materiality}

\section{Thaís Cristina Martino Sehn, Suely Fragoso, José Luís Farinatti Aymone}

The objective of this research was to map the artifacts that are currently denominated 'digital books', characterizing them through the cross-analysis of the specific resources of the digital medium with the main specificities of printed books. The methodology used included bibliographic review and observation of the subject of study. In this study, the book was perceived as an artifact with flexible properties, deciding, therefore, to propose a series of principles that together can be used to characterize this type of publication, regardless of whether it is digital or printed format. Therefore, the conclusion was reached that the eBook is a digital content with the same characteristics of a book and that in addition to text and image, they can explore digital media resources such as interactivity, sound, video, and animation. Through the predominant characteristics of the analyzed artifacts, the following types of digital books were identified: customizable, PDF, digitized, multimedia and interactive.

Keywords: design, e-book, remediation. 


\section{La caracterización de los libros digitales a partir de su materialidad}

\section{Thaís Cristina Martino Sehn, Suely Fragoso, José Luís Farinatti Aymone}

El objetivo de esta investigación es el de mapear los artefactos que actualmente se denominan "libros digitales", caracterizándolos a partir de la comparación de los recursos propios del medio digital con las principales especificidades de los libros impresos. La metodología utilizada abarca la revisión bibliográfica y la observación del objeto de estudio. En este análisis el libro es percibido como un artefacto con propiedades flexibles, decidiendo, por ello, proponer una serie de principios que juntos puedan ser utilizados para caracterizar este tipo de publicaciónes, independientemente de que se hayan producido en un medio digital o impreso. Por lo tanto, se llega a la conclusión de que el e-book es un contenido digital con las mismas características que un libro, que puede explorar, además del texto y de la imagen, los recursos propios de los medios digitales, tales como la interactividad, el sonido, el vídeo y la animación. A través de las características predominantes de los artefactos analizados, se identifican los siguientes tipos de libros digitales: adaptable, PDF, digitalizado, multimedia e interactivo.

Palabras clave: diseño, e-book, libro electrónico, remediación. 